\title{
A small-molecule screen reveals novel modulators of MeCP2 and X-chromosome inactivation maintenance
}

Hyeong-Min Lee ${ }^{1,2,3}$, M. Bram Kuijer ${ }^{1}$, Nerea Ruiz Blanes ${ }^{4}$, Ellen P. Clark ${ }^{1}$ Megumi Aita', Lorena Galiano Arjona ${ }^{4}$, Agnieszka Kokot ${ }^{5}$, Noah Sciaky ${ }^{6}$, Jeremy M. Simon ${ }^{2,7}$, Sanchita Bhatnagar ${ }^{5}$, Benjamin D. Philpot ${ }^{1,2}$ and Andrea Cerase ${ }^{4^{*}}$ (DD

\begin{abstract}
Background: Rett syndrome (RTT) is a neurodevelopmental disorder caused by mutations in the X-linked methylCpG binding protein 2 (MeCP2) gene. While MeCP2 mutations are lethal in most males, females survive birth but show severe neurological defects. Because $\mathrm{X}$-chromosome inactivation $(\mathrm{XCl})$ is a random process, approximately $50 \%$ of the cells silence the wild-type (WT) copy of the MeCP2 gene. Thus, reactivating the silent WT copy of MeCP2 could provide therapeutic intervention for RTT.

Methods: Toward this goal, we screened $~ 28,000$ small-molecule compounds from several libraries using a MeCP2-luciferase reporter cell line and cortical neurons from a MeCP2-EGFP mouse model. We used gain/increase of luminescence or fluorescence as a readout of MeCP2 reactivation and tested the efficacy of these drugs under different drug regimens, conditions, and cellular contexts.

Results: We identified inhibitors of the JAK/STAT pathway as XCl-reactivating agents, both by in vitro and ex vivo assays. In particular, we show that AG-490, a Janus Kinase 2 (JAK2) kinase inhibitor, and Jaki, a pan JAK/STAT inhibitor, are capable of reactivating MeCP2 from the inactive $X$ chromosome, in different cellular contexts.
\end{abstract}

Conclusions: Our results suggest that inhibition of the JAK/STAT pathway is a new potential pathway to reinstate MeCP2 gene expression as an efficient RTT treatment.

Keywords: Rett syndrome, MeCP2, X-chromosome inactivation, AG490, Janus Kinase, Janus Kinase inhibitors, JAK STAT, PI3K/ATK pathways

\section{Introduction}

Rett syndrome (RTT) is a severe neurodevelopmental disorder often classified as an autism spectrum disorder (ASD). About $90 \%$ of reported cases of individuals with RTT inherit de novo mutations of the methyl-CpGbinding protein $2(\mathrm{MeCP} 2)$ gene [1]. The detailed mechanism of how $\mathrm{MeCP} 2$ mutations lead to RTT is largely unknown; however, mutations in $\mathrm{MeCP} 2$ are associated

* Correspondence: a.cerase@qmul.ac.uk

${ }^{4}$ Blizard Institute, Queen Mary University of London, London, UK

Full list of author information is available at the end of the article with defects in neuronal development and synapse formation [2, 3]. A deficiency of $\mathrm{MeCP} 2$ leads to immature synaptic development in the cortex [4-6] and disruption of the metabolism of brain cholesterol, resulting in abnormal neuronal function [7, 8]. Mutations affecting the nuclear localization signal region of $\mathrm{MeCP} 2$ or early truncating mutations are responsible for a severe phenotype in comparison to missense mutations, whereas $\mathrm{C}$-terminal mutations are associated with milder phenotypes $[9,10]$. As $M e C P 2$ is also expressed in glia,

C C The Author(s). 2020 Open Access This article is licensed under a Creative Commons Attribution 4.0 International License, which permits use, sharing, adaptation, distribution and reproduction in any medium or format, as long as you give appropriate credit to the original author(s) and the source, provide a link to the Creative Commons licence, and indicate if changes were made. The images or other third party material in this article are included in the article's Creative Commons licence, unless indicated otherwise in a credit line to the material. If material is not included in the article's Creative Commons licence and your intended use is not permitted by statutory regulation or exceeds the permitted use, you will need to obtain permission directly from the copyright holder. To view a copy of this licence, visit http://creativecommons.org/licenses/by/4.0/ The Creative Commons Public Domain Dedication waiver (http://creativecommons.org/publicdomain/zero/1.0/) applies to the data made available in this article, unless otherwise stated in a credit line to the data. 
dysfunction in glial cells could also be involved in the pathogenesis of RTT [11].

The clinical symptoms in individuals with RTT include breathing abnormalities, loss of speech, motor impairments, loss of purposeful hand movements, and repetitive stereotypical movements [12,13]. RTT individuals must receive lifelong care because there is currently no cure, although multiple approaches have been used to provide symptomatic relief. For example, antiepileptic drugs provide symptomatic relief for many of the $\sim 60 \%$ of RTT individuals affected by seizures $[14,15]$. Breathing irregularities and sleep problems in RTT individuals can also be symptomatically treated [16-19]. Other treatment options include physical therapy, speech therapy, occupational therapy, and psychosocial support for families. Management of these conditions can substantially improve the quality of life in individuals with RTT [20].

The $M e C P 2$ gene is located on the $\mathrm{X}$ chromosome in both mice and humans. The gene undergoes XCI in females [21], acquiring multiple repressive DNA and histone modifications [22-29]. As XCI is a random process, roughly $50 \%$ of each inherited $\mathrm{X}$ chromosome is expressed. Consequently, in the case of an X-linked mutation, $\sim 50 \%$ of wild-type (WT) and mutated X chromosomes are silenced [21]. This silent WT copy on the inactive $\mathrm{X}$ chromosome (Xi) represents an important backup that can be potentially unlocked to produce WT protein.

The reversal of XCI, or better yet the specific reversal of $\mathrm{MeCP} 2$ inactivation, offers a promising treatment opportunity for RTT and has been attempted by several groups [30-34]. The feasibility of this approach was first demonstrated by the Green lab, who demonstrated that pharmacologically targeting XCI factors such as ACVR1 and PDPK1 can reactivate $M e C P 2$ [30]. Subsequently, a small-molecule screen performed by the Lee lab has shown that VX680, an inhibitor of Aurora kinases (AurK), reactivates $\mathrm{MeCP} 2$ if primed by 5 -Aza-dC-mediated DNA demethylation [31]. Another study from the Bedalov lab showed that targeting BMP/TGF-beta signaling holds potential for reactivating $\mathrm{MeCP} 2$ on the $\mathrm{Xi}$ [33]. And recently, central nervous system coadministration of GSK650394 (SGK1 inhibitor) and LDN193189 (ACVR1 inhibitor) was shown to reactivate $M e C P 2$ and reverse RTT phenotypes in a mouse model [32]. Collectively, these studies demonstrate the promise of reactivating $\mathrm{MeCP} 2$ by disrupting XCI. However, all these approaches have challenges that still need to be overcome. For example, potential pharmacological treatments (1) can produce cytotoxicity in neuronal cells when administered at higher concentrations [35]; (2) have targets that are barely expressed in neurons, as in the case of AurkA/B [31] (brainrnaseq.org and proteinatlas.com); (3) are not yet shown to reactivate $M e C P 2$ in neurons [33]; and/or (4) have to be assessed for their ability to produce broad CNS bioavailability with peripheral administration [32]. Until these challenges can be overcome and a treatment for RTT is available, there is an urgent need to continue to identify new $\mathrm{MeCP} 2$ activators and to optimize these and previously identified $\mathrm{MeCP} 2$ activators for safety and efficacy.

Here we employed a phenotypic screen $(\sim 28,000$ compounds) to identify novel compounds that can effectively reactivate the $M e C P 2$ gene. We found that two JAK/STAT pathway inhibitors, AG490 and Jaki, could reproducibly reactivate $M e C P 2$. While the mechanism, efficacy, and safety of targeting this pathway must be thoroughly investigated, our results suggest that JAKSTAT inhibitors offer an additional approach that needs to be explored for the possible treatment of RTT and other X-linked disorders.

\section{Material and methods Animals}

All animals were maintained and used according to the Institutional Animal Care and Use Committees of the University of North Carolina at Chapel Hill. Mice were maintained on a 12:12 h light:dark cycle and given ad libitum access to food and water. To produce embryonic cortical neurons for screening, wild-type (WT) female mice were crossed with male mice carrying EGFP-tagged $\mathrm{MeCP} 2$ provided by Adrian Bird at the University of Edinburgh. At 14.5 days post-conception (E14.5), females were terminated to obtain embryos. All genotypes of the offspring were validated by PCR of DNA collected from tail biopsy.

\section{Chemical libraries}

Individual compounds in the chemical libraries were pre-dissolved in DMSO at a concentration of $10 \mathrm{mM} /$ compound. The drug plates for screening were prepared at a final concentration of $1 \mu \mathrm{M}$ in culture medium. $0.1 \%$ DMSO vehicle controls were utilized for screening and all validating experiments. Fresh compounds, AG490 and Jaki, were purchased from Selleckchem and Cayman chemicals, respectively, for compound validation. The full chemical libraries we screened are listed in supplementary Table 1.

\section{Cell culture and drug treatment Neuron cultures}

Cortical neuron cultures were performed by following a previously established protocol [36]. Briefly, neurons were isolated from EGFP reporter mice carrying EGFPtagged $\mathrm{MeCP} 2\left(\mathrm{MeCP}^{\mathrm{EGFP} /+}\right)$ or WT mice at E14.5 and allowed to grow for 7 days in vitro (DIV). Neurons were seeded at 20,000 cells per well in 384-well plates and maintained in Neurobasal media supplemented with 
B27, penicillin/streptomycin, and Glutamax (Invitrogen). At DIV 7, small molecules at a final concentration of $1 \mu \mathrm{M}$ were added for 3 days. Cortical neurons were also plated at $1 \times 10^{6}$ cells per well in a 6-well plate for western blot analysis. Ex vivo cortical neurons were treated with AG490 (1 and $3 \mu \mathrm{M})$ or Jaki $(1$ and $3 \mu \mathrm{M})$ twice for 3 days each.

\section{Fibroblast cultures}

Mouse tail fibroblast cells carrying an inactive or active $\mathrm{MeCP} 2$-luciferase reporter (clones Xi8 and Xa3, respectively [33]) were cultured and maintained in DMEM supplemented with $10 \%$ FBS and penicillin/streptomycin. Fibroblast cells were plated at 20,000 cells per well in 96-well plates 1 day before treatment. The following day, small molecules (compound libraries) at a final concentration of $1 \mu \mathrm{M}$ or 5 -Aza $(10 \mu \mathrm{M}$ as a control) were added to the cells. The cells were treated for 3 days and tested by means of luminescence assays in a high-throughput manner. For compound validation, the fibroblast cells were treated with AG490 (1 and $3 \mu \mathrm{M})$, Jaki (1 and $3 \mu \mathrm{M})$, or 5 -Aza $(10 \mu \mathrm{M})$, respectively, for 3 days each or twice for 2 days.

\section{THX88 and $\mathrm{C} 2 \mathrm{C} 12$ cultures}

THX88 is a hamster cell line, containing a single human $\mathrm{X}$ chromosome in the inactive state (Xi) [37]. THX88 and $\mathrm{C} 2 \mathrm{C} 12$, a fully differentiated female myoblast line [38], were maintained in DMEM supplemented with $10 \%$ FBS and penicillin/streptomycin. One day after plating the cells in 6 or 4 multi-well plates $(150,000$ cells/ well), the cells were treated with $3 \mu \mathrm{M}$ of AG490 or 1 $\mu \mathrm{M}$ Jaki or $10 \mu \mathrm{M}$ of 5 -Aza for 4 days.

\section{H4SV cultures}

H4SV mouse fibroblast cells were cultured and maintained in DMEM supplemented with $10 \%$ FBS and penicillin/streptomycin. In brief, 300,000 cells were seeded into each well of a 6-well plate and cultured $24 \mathrm{~h}$ before any treatment. Cells were further treated with AG490 or Jaki during HAT selection for up to 12 days. Surviving cells were counted and measured for GFP reactivation by qPCR (see below) [30, 32].

\section{Fluorescence immunocytochemistry and high-content imaging}

Immunocytochemistry and high-content imaging were performed as previously described [36, 39], using rabbit anti-GFP primary (1:1000, Novus Biologicals) and goat anti-rabbit AlexaFluor-488 secondary (1:500, Invitrogen) antibodies. Hoechst staining was simultaneously performed to visualize and count nuclei. Briefly, images of the immunofluorescence-processed neurons stained for Hoechst and AlexaFluor-488 were analyzed using a BD
Pathway 855 high-content imaging fluorescence microscope. MeCP2 reactivation was detected by means of fluorescence intensity in drug-treated cells (at single cell level) vs vehicle control. We defined as potentially active drugs compounds eliciting a consistent increase in the mean EGFP fluorescence, across quadruplicate wells and minimal or no cytotoxicity measured by Hoechst-stained nuclear structure and cell viability. All images were taken by BD Pathway 855, a high-content imager, and processed by CellProfiler [40] to analyze the number of positive GFP cells.

\section{Luminescence high-throughput screen}

Luminescence-based high-throughput screen was performed using mouse fibroblast cells carrying an inactive MeCP2-luciferase reporter (Xi8). About 20,000 cells per well were plated into 96-well plates 1 day before compound treatment ( $n=3$ per $1 \mu \mathrm{M}$ of compounds). Three days after the small-molecule treatment, the cells were rinsed with 1x PBS, and Bright-Glo (Promega) (mixture of substrate and lysis buffer) was directly added to cells in 96-well plates. Fifteen minutes after allowing cell lysis and equilibrating the cell plates in the dark at room temperature, a MicroBeta Trilux (Perkin Elmer) microplate reader was used to measure luminescence from the reactivated MeCP2-luciferase. 5-Aza was used as a positive control [33], and a twofold or more change in relative luciferase unit was considered an active compound (see also Supplementary Table 2).

\section{Western blot analysis}

Western blot analysis was performed to validate the reactivation of $\mathrm{MeCP} 2$ protein levels. Six days after small-molecule treatment $(2 \times 3$-day treatment), neurons in 6-well plates were harvested to extract total proteins using RIPA buffer. Bradford assays were used to determine protein amount, and $30 \mu \mathrm{g}$ of total protein was resolved in SDS-PAGE to analyze changes in MeCP2EGFP protein levels. Primary antibodies were rabbit antiGFP (1:1000, Novus Biological) and mouse anti-actin (1: 5000, Sigma). Secondary antibodies were HRP-conjugated anti-rabbit (1:1000, Vector lab) and anti-mouse (1:1000, Vector Lab). Chemiluminescence produced by ECL substrate (BioRad) was detected by an Amersham Imager 600 (GE Life Sciences).

\section{RT-PCR and qPCR}

RT-PCR and quantitative real-time PCR (qPCR) were performed using previously reported protocols [39]. Total RNA was extracted by using Direct-zol RNA kit and following the manufacturer's protocol (Zymo Research). cDNA pool was synthesized by qScript cDNA Supermix (Quantabio) using $2 \mu \mathrm{g}$ of total RNA. cDNA from clone Xi8 and Xa3 RNA was further used for qPCR 
to analyze reactivated mouse $M e C P 2$. qPCR was performed using SsoAdvanced Universal SYBR green Supermix (BioRad). The primer sets were $\beta$-actin (forward, 5'-AGAGCTACGAGCTGCCTGAC-3'; reverse, 5'-AGCACTGTGTTGGCGTACAG-3), mouse $M e C P 2$ (forward, 5'-CATACATAGGTCCCCGGTCA3'; reverse, 5'-CAGGCAAAGCAGAAACATCA-3'), mouse Xist (forward 5'-GGTTCTCTCTCCAGAAGC TAGGAAAG-3'; reverse, 5'-GGTAGATGGCATTGTG TATTATATGG-3'), and mouse Rnf12 (forward, 5'CTTGGATCGGGAAGAGGCTT-3'; reverse, 5'-TTCA CCTGGGGTGCCCAGCA-3'). qPCR was performed using QuantStudio thermocycler (Thermo Fisher) with the following conditions: $95^{\circ} \mathrm{C}$ for $5 \mathrm{~min}$ and followed by 40 cycles of $95^{\circ} \mathrm{C} 10 \mathrm{~s}, 60^{\circ} \mathrm{C} 1 \mathrm{~min}$. Relative quantity (RQ) was determined after normalized $\Delta \Delta C t$ was calculated.

\section{Experiments in the Xi-containing line}

RNA was extracted using a kit from Qiagen (RNAesy) and subjected to DNAse treatment (Turbo DNAse, Ambion) followed by reverse transcriptase and qRTPCT analysis (SuperScript III, Thermo; BioRad SYBR green). Primers used were hMECP2-nF: GGCAAGCA TGAGCCCGTGCAGCCA, hMECP2-nR: GCCGGG GCGGAGCCTGACCCTTCT; humanXISTF: TGGAGG GAAACAGTATACCCC, humanXISTR: ATTTATGT TGGTTCTTGTGCCC; human Rnf12, RLIMEx1F: ATTGGAGGCGGGCTTGAG, RLIMEx2R: GCAGACTGATCACCACTTCC; hamsterGapdhF: GAGACGCAAT GGTGAAGGTC, hamsterGapdhR: GCCTTGACTG TGCCTTTGAA.

Mouse primers used for testing gene reactivation in the HAT selection medium were Mecp2 F: CATGGTAGCT GGGATGTTAGG; Mecp2 R: GCAATCAATTCTACTT TAGAGCG; hprt F: AAGCTTGCTGGTGAAAAGGA; and Hprt R: TTGCGCTCATCTTAGGCTTT. Relative quantity (RQ) was determined after normalized $\Delta \Delta C t$ was calculated.

\section{Statistical analysis}

Significant $(p<0.05)$ changes in the MeCP2-EGFP, MeCP2-luciferase levels, and up- or downregulation of tested genes were determined by one-way ANOVA with Dunnett's multiple comparison test or Student's $t$ tests.

\section{Results}

\section{AG490 is a potential reactivator of $\mathrm{X}$-linked genes}

To identify compounds that are capable of reactivating the inactive copy of $\mathrm{MeCP} 2$, we employed highthroughput, high-content screens using multiple chemical libraries. We screened over 28,000 compounds in two different cell-based models simultaneously. First, we tested our libraries using transformed mouse tail fibroblast cells carrying a MeCP2-luciferase reporter on the inactive $\mathrm{X}$ chromosome (clone Xi8) [33]. Luminescence-based screens were performed in a 96well plate format. Using this approach, we identified AG490 (Fig. 1a, Suppl. Fig. 1A and Table S2) as a potential $\mathrm{MeCP}$-reactivating agent. We used 5-azacytidine (5-Aza), a known XCI-reactivating agent, as a positive control [33]. The $\mathrm{EC}_{50}$ of 5-Aza and $\mathrm{AG490}$ was $5.88 \mu \mathrm{M}$ and $0.19 \mu \mathrm{M}$, respectively, in our cell-based screening model, and their efficacy (i.e., level of MeCP2 reactivation) was comparable $\left(E_{\max }=120 \sim 125 \mathrm{RLU}\right.$; Fig. $1 b)$. The identified MeCP2-reactivating compounds were further validated using western blot analysis, RT-PCR, and quantitative real-time PCR in different cellular models (see below). We also tested previously published MeCP2 reactivation compounds (LY294002, OSU03012, BX912 [30]; K02288 [32]; MNL8237, VX680 [31]; see also the "Introduction" section). These compounds failed to reactivate $\mathrm{MeCP} 2$ under our experimental conditions (Fig. 1a, green dots).

We further tested the small-molecule libraries in primary cortical neurons generated at embryonic day 14.5 from mice carrying a previously established MeCP2EGFP reporter [41], with the caveat that the sensitivity of this assay was reduced given that we had to detect increases above a much higher basal level of MeCP2 expression. Although AG490 was identified as a potential activator in the fibroblast cells, the neuronal screen identified no small molecules at the tested concentrations that could consistently reactivate $\mathrm{MeCP} 2$ above detection limits in primary neurons (see the "Material and methods" section). Thus, we explored additional drug regimens in an attempt to measure $\mathrm{MeCP} 2$ activation with our potential active compounds (see below).

\section{JAK/STAT inhibitors can reactivate genes on the inactive $\mathrm{X}$ chromosome}

To validate our primary hit and to explore its possible mechanism of action, we tested two Janus kinase inhibitors (AG490 and Jaki), for their ability to reactivate $\mathrm{MeCP} 2$ and $\mathrm{Xi}$ in neurons and independent cell lines. AG490 is a Janus Kinase 2 (JAK2) inhibitor used for glioma therapy [42], but it also has inhibitory activity toward the epidermal growth factor receptor (EGFR) mediating PI3K/AKT signaling [43]. Jaki is a pan JAK/ STAT inhibitor [44]. Furthermore, it has been previously suggested that Jaki can upregulate $M e C P 2$ in mouse embryonic stem cells [45]. Thus, we used quantitative PCR (qRT-PCR) to test how different doses and time courses of AG490 affected $M e C P 2$ reversal in comparison with 5-Aza (Fig. 1c, d, and Suppl. Fig. 1B).

First, we tested whether AG490 and Jaki treatments affect the mRNA expression of $\mathrm{MeCP} 2$ from the inactive and active $\mathrm{X}$ chromosome (Xi/Xa) in two clonal cell 
A

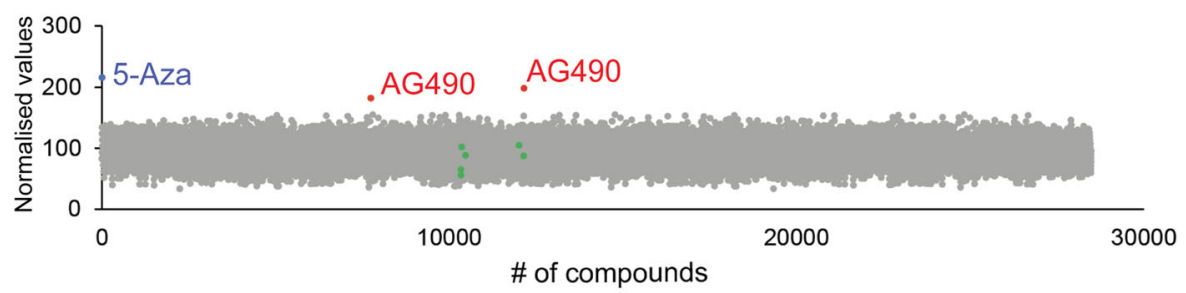

B
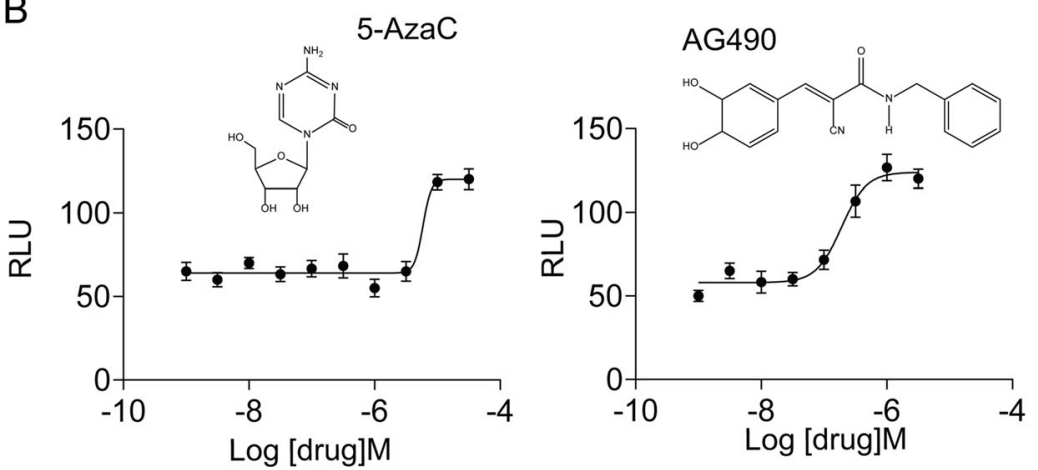

C
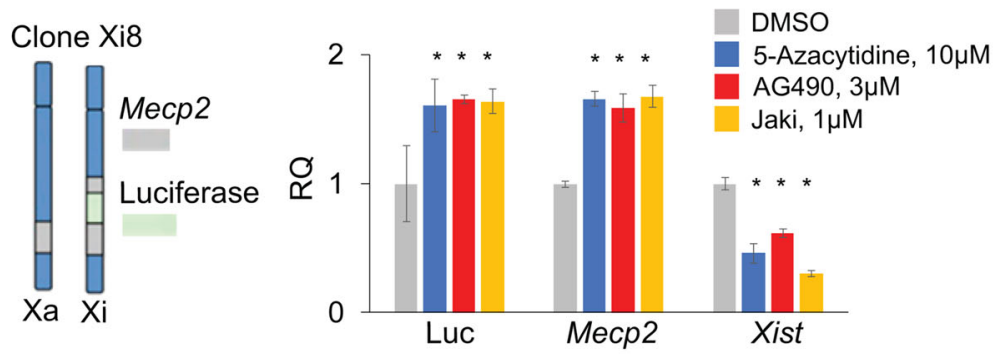

$\mathrm{D}$
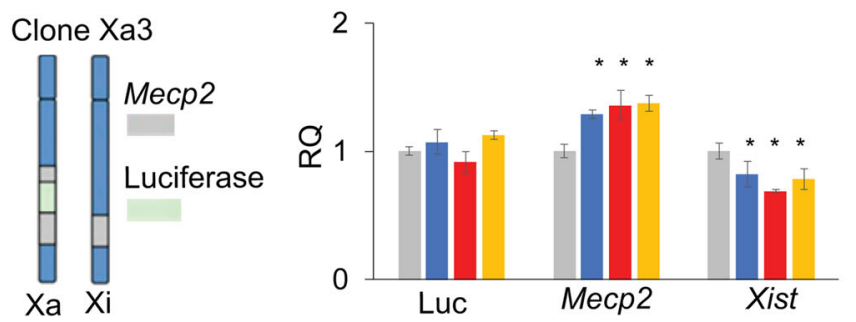

Fig. 1 Luminescence-based screen identifies AG490 and Jaki as potential reactivators of genes on the inactive X chromosome. a Dot plot indicating the percentage of luciferase activation per drug using the Xi8 fibroblast cell line reporter for MeCP2 activation over the control (normalized values; see the "Material and methods" section). In red, we show AG490, in blue 5-Aza, and in green compounds previously reported to reactivate MeCP2 using different protocols (LY294002, OSU-03012, MLN8237, BX-912, K02288, VX-680; see the "Introduction" and the "Results" sections for more details). b Top: Chemical structure of 5-azacytidine (5-Aza), a known reactivator of MeCP2, and AG490. Bottom: Dose response of 3-day treatment of 5-Aza or AG490 in Xi8 fibroblast cells ( $n=3$, one representative graph shown here from three independent assays). c Left: Xi8 clone showing MeCP2 and MeCP2-luciferase genes on the inactive chromosome. Right: qRT-PCR data showing the effect of the indicated drug treatments on luciferase (Luc), Mecp2, and Xist mRNA levels; mean ( \pm SEM) are shown, ${ }^{*}$ statistical significance, $p \leq 0.05$ ( $n=3$ per compounds, the average of three biological replicates are shown). $\mathbf{d}$ Left: Xa3 clone showing MeCP2 and MeCP2-luciferase genes on the active chromosome, respectively. Right: qRT-PCR data showing the effect of the indicated drug treatments on luciferase (Luc), Mecp2, and Xist mRNA levels; mean ( \pm SEM) are shown, ${ }^{*}$ statistical significance, $p \leq 0.05$ ( $n=3$ per compounds, the average of three biological replicates are shown) 
lines. Clones Xi8 and $\mathrm{Xa} 3$ are mouse fibroblast lines carrying a $M e C P 2$-luciferase reporter on either the inactive $\mathrm{X}$ (Xi) or active X (Xa) chromosome, respectively (Fig. 1b, c). We found that AG490 and Jaki (and 5-Aza-positive control) treatments increased the expression of MeCP2 and the luciferase reporter and downregulated Xist in the Xi8 clone (Fig. 1b). We similarly found that AG490, Jaki, and 5Aza increased $M e C P 2$ and decreased Xist levels in the Xa3 clone, without affecting luciferase levels (Fig. 1c). Taken together, these data suggest that the increase in $M e C P 2$ expression is driven from the $\mathrm{Xi}$ rather than the $\mathrm{Xa}$.

We next tested the effect of different AG490 concentrations and time courses on $\mathrm{X}$-linked gene regulation (see also the "Material and methods" section). We report that a single treatment of AG490 (3 $\mu \mathrm{M})$ is capable of reactivating $M e C P 2$ in the fibroblast cells without altering RNA expression of Xist or Rnf12, a strong Xist activator (Fig. S1B, Left). In double-dose treatments, we observed a similar upregulation of $\mathrm{MeCP} 2$ (and its luciferase reporter), and a stronger downregulation of Xist and Rnf12 (Fig. S1B, see the "Material and methods" section). Differences in the treatment regimen can potentially explain the lack of effect of AG490 treatment in the cortical neuronal screen (i.e., a stronger Xist/Rnf12 downregulation is needed for XCI reversal in neurons, see also the "Discussion" section). Overall, these data support that AG490 and Jaki are potential reactivating agents for $\mathrm{X}$-linked genes on the inactive $\mathrm{X}$ chromosome.

We also tested a combination of 5-Aza and AG490 on the Xi8 clone. Surprisingly, the combination of these drugs does not have a synergistic effect on MeCP2 overall reactivation (Fig. S2A, S2B). This observation suggests that $\mathrm{MeCP} 2$ reactivation elicited by these drugs might be driven through a pathway or mechanism that may also modulate DNA demethylation.

We next examined whether Xist downregulation might be due to drug-induced, Xist detachment from the Xi. To this end, we performed Xist RNA-FISH on fully differentiated female cell lines $(\mathrm{C} 2 \mathrm{C} 12)$ treated for 4 days with AG490/Jaki (Fig. S2C). Upon treatment, we did not observe any major change in Xist localization or abundance on the $\mathrm{Xi}$, suggesting that Xist downregulation is likely happening at a transcriptional level.

\section{AG490 effectively upregulates MeCP2 in cultured cortical} neurons and additional cellular contexts

Given the improved knockdown of Xist with a double treatment of AG490, we used this approach to reexplore its ability to activate $M e C P 2$ in ex vivo neurons. These cultured neurons display a mosaic expression of MeCP2 and MeCP2-EGFP, in which we detect a basal expression of MeCP2-EGFP above a set threshold in 20$25 \%$ of cells (DMSO vehicle-treated cell in Fig. 2a, b, and Suppl. Fig. 1C). We found that two treatments of AG490 $(3 \mu \mathrm{M})$ successfully upregulated MeCP2 in the cultured primary cortical neurons, such that $~ 50 \%$ of cells now expressed MeCP2 above threshold (Fig. 2a, b, and Suppl. Fig. 1C). We performed western blot analysis to verify that AG490 upregulated MeCP2-EGFP at the protein level in primary neurons (Fig. 2c). We also found that Jaki $(1$ and $3 \mu \mathrm{M})$ could increase MeCP2-EGFP expression at the tested concentrations (Fig. 2c and Suppl. Fig. 1C).

To further test the ability of AG490 and Jaki to reactivate $M e C P 2$, we tested the compounds in additional cellular contexts. We found that a 4-day treatment of AG490 induces a small, non-significant reactivation of the human $M e C P 2$ gene in a chimeric cell line carrying a single human inactive $\mathrm{X}(\mathrm{Xi})$ chromosome in a hamster background [37] (Fig. 3a). Jaki treatments on the other hand increased $\mathrm{MeCP} 2$ reactivation more robustly than AG490, although the extent of MeCP2 reactivation did not reach statistical significance due to interexperiment variation (Fig. 3a). In this chimeric cell line, 5-Aza significantly reactivated the human $M e C P 2$ and RNF12 genes to varying degrees, without significantly altering XIST levels.

We also tested AG490 and Jaki in a mouse fibroblast cell line, H4SV, in order to provide additional insights into cell-type bias against drug responses. H4SV cells carry a deletion of the hypoxanthine phosphoribosyl transferase (Hprt) on the active $\mathrm{X}$ and undergo cell death during hypoxanthine-aminopterin-thymidine (HAT) selection (Fig. 3b). AG490 treatment for 7 days allowed the cells to increase their survival rate during HAT selection for 12 days (Fig. 3b), suggesting that AG490 reactivates the Hprt gene on inactive X chromosome and providing additional orthogonal evidence that AG490 likely increases MeCP2 expression by activation of the Xi. Hprt and MeCP2 reactivation were also confirmed at the RNA level by qRT-PCR (Fig. 3c).

\section{Discussion}

Previous studies demonstrating the ability of genetic manipulations or small molecules to reactivate $M e C P 2$ on the inactive $\mathrm{X}$ chromosome have shown the promise of this approach as a potential RTT treatment [30-33], yet none of the existing drugs has been applied to preclinical or clinical trials. There is thus a need to find additional $\mathrm{MeCP} 2$-reactivating compounds, with the expectation that an $M e C P 2$-reactivating compound will eventually be advanced to the clinic. Here we identified two additional molecules, AG490 and Jaki, that can reactivate $\mathrm{MeCP} 2$ from Xi. Since both compounds inhibit the JAK/STAT pathway, we tested several additional molecules in the JAK/STAT inhibitor family, but we identified no additional Janus kinase inhibitors that could reactivate 


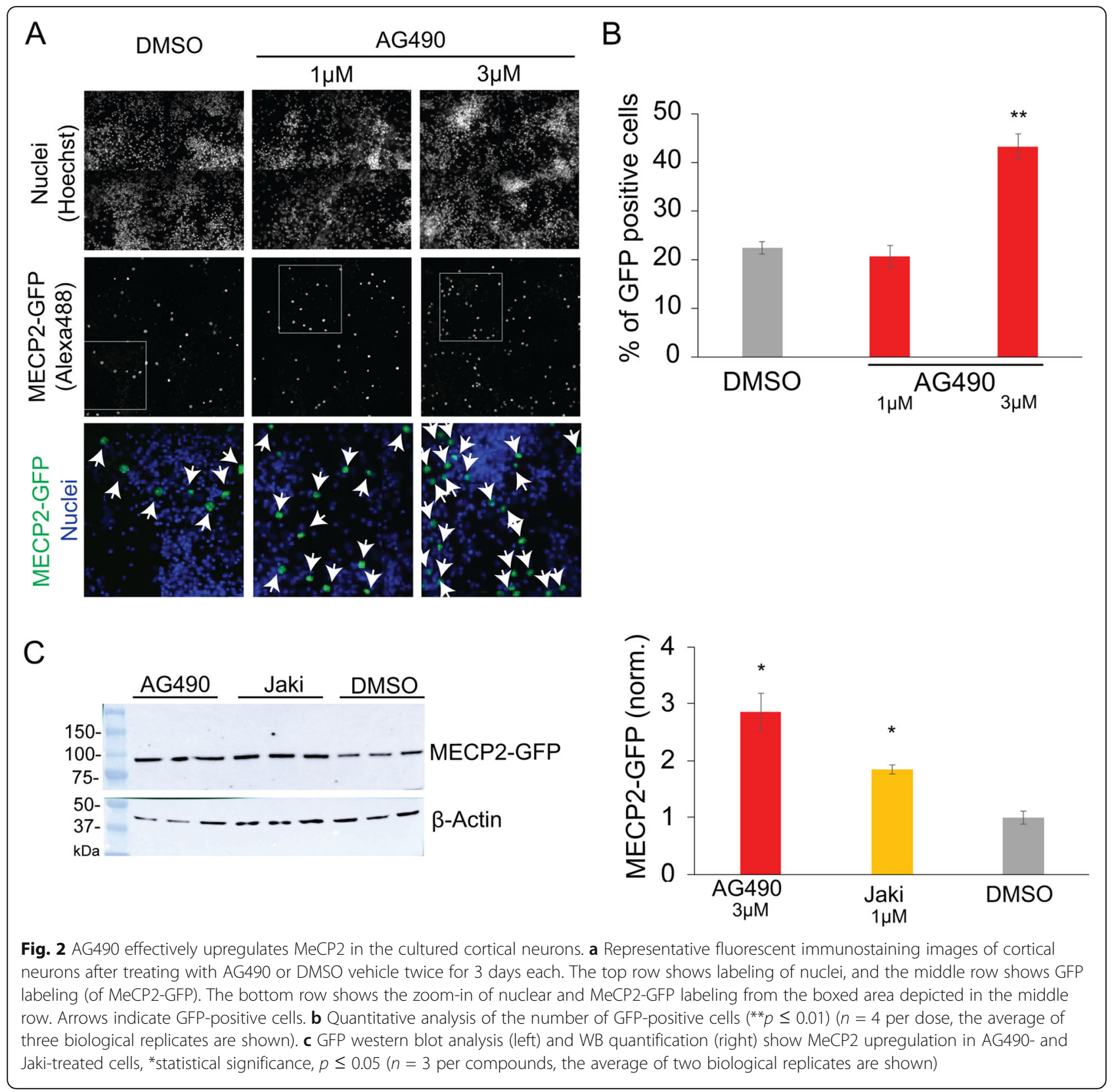

$M e C P 2$ (data not shown). Our data suggest that there is a preferential role for specific classes of Janus kinases in $\mathrm{XCI}$ maintenance or that these compounds are working through off-target effects. Alternatively, different dose regimens might be required to produce reactivating effects in a drug-dependent manner, suggesting that a large parameter space of dosing regimens must be explored to identify an effective and reliable $\mathrm{MeCP} 2$-reactivating protocol.

We expect time and cellular context to be particularly critical factors underlying the activity of these drugs, perhaps because of the temporal dynamics needed to produce DNA demethylation or long-term transcriptional changes $[46,47]$. In support of this hypothesis, double treatments of AG490 had reactivating effects in primary cortical neurons, whereas single treatments did not. Furthermore, in the fibroblast clone Xi8, longer, double-dose treatments of AG490 produced significant downregulation of Xist and Rnf12, two key players of XCI [48], whereas the shorter/single administrations of AG490 did not (Suppl. Fig. 1B). Surprisingly, the double treatment (5-Aza + Janus kinase inhibitor) did not elicit a stronger $\mathrm{MeCP} 2$ reactivation, suggesting that AG490/Jaki-mediated MeCP2 reactivation could work through a mechanism that mechanistically overlaps with that of 5-Aza. We have also shown $10-20 \%$ MeCP2 


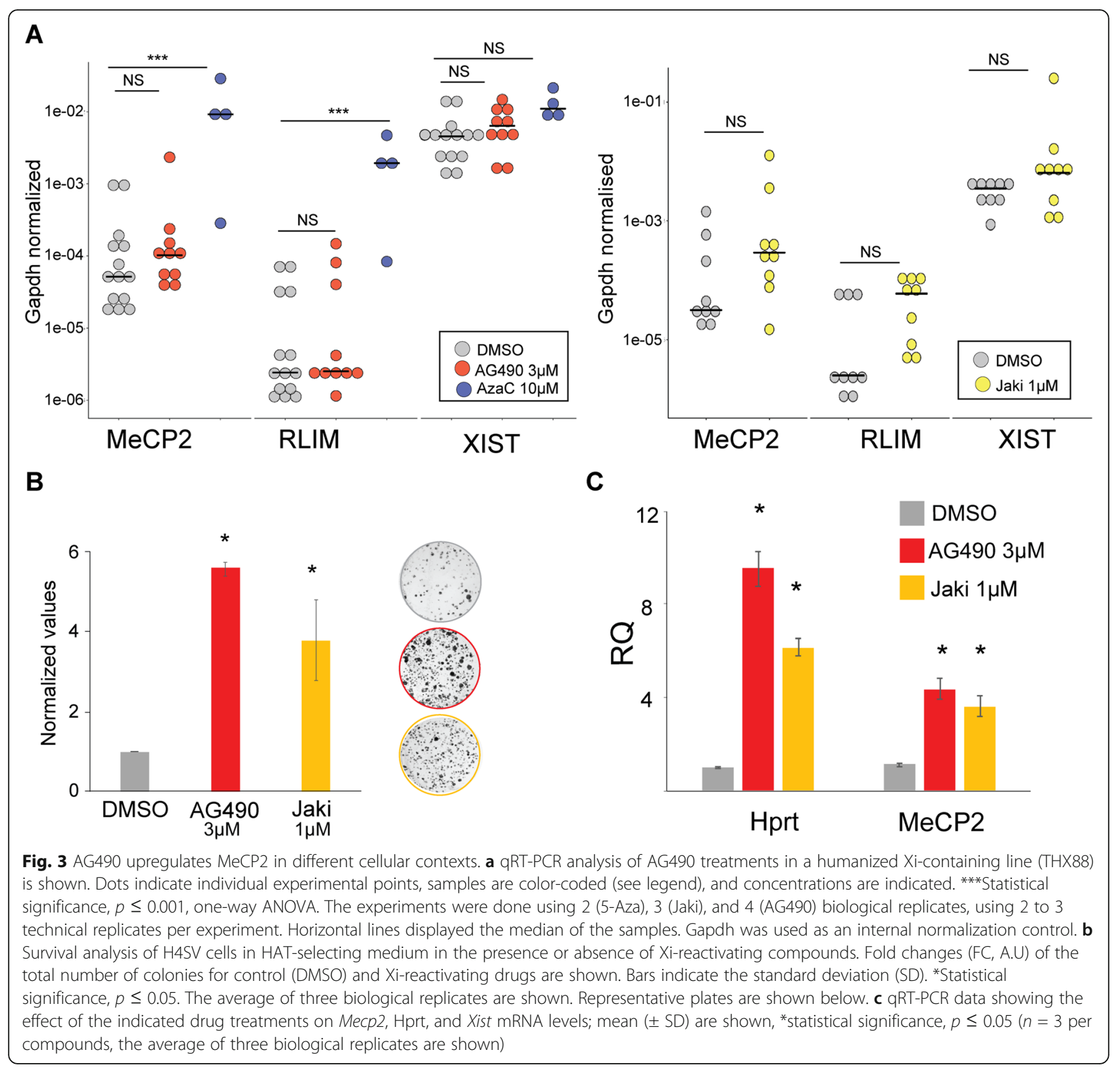

reactivation in neurons at a single cell level (Fig. 2, Suppl. Fig. 1C) and modest MeCP2 reactivation by qRTPCR and luminescence assays (Fig. 1, Suppl. Fig 1/2, 3B). The apparent discrepancies in measured reactivation levels are likely due to inherent methodological differences in the employed techniques (i.e., single vs population analysis).

While these data demonstrate the importance of temporal aspects when attempting to reactive $\mathrm{MeCP} 2$ (discussed above), the cellular context is also an important variable. For example, while AG490 and 5-Aza reactivated $\mathrm{MeCP} 2$ in our mouse fibroblast cell lines, only 5-Aza treatments increased MeCp2 levels in the hamster/human chimeric cell line. These distinctive responses can also be linked to differences in XCI profiles between different cell lines and likely linked to Xist regulation [45] and suggest there may be species-specific differences (i.e., mouse vs human).

With the exception of the results in the chimeric line, which might not fully recapitulate the complexity of physiological XCI, our results suggest that AG490/JAKI may reactivate $\mathrm{MeCP} 2$ by transcriptional downregulation of Xist. It is likely that neurons and other cell lines rely more robustly on Xist-mediated silencing than DNA methylation at regulatory regions. Indeed, it is clear that some cell lines are more dependent than others on Xist silencing, which may explain our observed differences between cell lines. For example, Xist RNA can be easily 
displaced from the $\mathrm{Xi}$ in cancer cells but not in primary cells [49]. Finally, while we did not extensively profile the reactivation of other $\mathrm{X}$-linked genes by JAKinhibitor treatment (other than Hprt), it is possible that these drugs can reactivate other X-linked genes such as $C D K L 5$ and FMR1. It remains to be addressed whether pretreatment levels of DNA methylation differ between cell lines and in their response to AG490. More studies are clearly needed to fully elucidate the mechanistic basis by which AG490 reactivates $M e C P 2$, and whether similar effects can be observed in human neurons.

\section{Conclusions}

In brief, our study shows that AG490 can reactivate the $\mathrm{XCI}$-silenced copy of the $\mathrm{MeCP} 2$ gene by in vitro and ex vivo approaches, and this general reactivation effect is observed across different types of cells (ex vivo neurons and fibroblasts) independently performed in three laboratories. Given the apparent safety of AG490 in neuronal culture treatments [50], our results indicate that AG490, and perhaps Jaki, could provide alternative approaches for reactivating $\mathrm{MeCP} 2$ and potentially treating RTT. However, extensive medicinal chemistry is likely needed to identify more efficacious compounds, and rigorous studies are needed to test mechanism, safety, and efficacy in vivo.

\section{Supplementary Information}

The online version contains supplementary material available at https://doi. org/10.1186/s11689-020-09332-3.

\section{Additional file 1: Supplementary figure 1. Compound validation under different treatment regimens. A) AG490 validation in 6-well plate for- mat. Relative Luminescence Units (RLU) is shown in function of the drug treatment for the clone Xi8. B) qRT-PCR of MeCP2, luciferase, Xist and Rnf12. Left: single treatment for the 72 hours regimen for clone Xi8. Right: double treatment regimen for $72 \mathrm{hr}$ each for clone Xi8. Bars indicate standard error of the mean (SEM). * indicates statistical significance, $p \leq$ $0.05, n=3$ per genes, average of two independent assays is shown) (C) Top: Representative fluorescent immunostaining images of cortical neu- rons in presence or absence of the compounds with double treatment (i.e. twice for $72 \mathrm{hr}$ ). Bottom: Quantitative analysis of number of GFP posi- tive cells. The \% of GFP positive cells increased in the presence of AG490 and Jaki with a double treatment regimen. Bars indicate standard error of the mean (SEM), samples are color-coded, concentrations are shown. ${ }^{*}$ in- dicates statistical significance, $p \leq 0.05, n=4$ per compound and dose, average of two independent assays is shown).}

Additional file 2: Supplementary figure 2. 5-Azacytidine and AG490 have no synergistic effect towards $M e C P 2$ reactivation. $\mathbf{A}$ and $\mathbf{B})$ Single and double treatments for 5-Azacytidine (5-Aza) and AG490 in Xi8 clonal line are shown. A) Relative Luminescence Units (RLU) in function of the drug treatment is shown. Bars indicate standard error of the mean (SEM). * indicates statistical significance, $p \leq 0.05)(n=3$ per genes, average of two independent assays is shown). B) qRT-PCR of MeCP2, luciferase, and Xist. Double treatment regimen for $72 \mathrm{hr}$ per treatments for clone Xi8 (see Materials and methods). Bars indicate standard error of the mean (SEM). * indicates statistical significance, $p \leq 0.05)(n=3$ per genes, average of two independent assays). DMSO: vehicle control 0.1\%, 5-Aza [10 $\mu \mathrm{M}]$, AG490 $[3 \mu \mathrm{M}], 5-A z a+A G 490$ : simultaneous treatment of two compounds [3 $\mu \mathrm{M}$ each], p(5-Aza) + AG490: p(5-Aza) indicated primed 5-Aza, meaning that priming by $5-A z a[3 \mu \mathrm{M}]$ was administered before before AG490 [3 $\mu \mathrm{M}]$ treatment (see Materials and Methods). C) Drug treatments do not affect Xist localization on the inactive $X$ chromosome in mouse cells. Xist RNAFISH in C2C12, a female fully differentiated mouse female cell line. Drug treatment was performed for 4 days and drugs concentrations are shown. Xist, red; DNA (DAPI) in blue are shown. 2Xi per cell are visible in most cells as this cell line is mostly tetraploid [38].

Additional file 3: Supplementary Table 1. This table shows the libraries used in this screen.

Additional file 4: Supplementary Table 2. This tables shows tall the drugs used in this screen and the \% of luciferase reactivation per drug (normalized values).

\section{Acknowledgements}

We would like to thank Dr. Adrian Bird at the University of Edinburgh for providing MeCP2-GFP reporter mice. We would like to thank Dr. Antonio Bedalov at the Fred Hutchinson Cancer Research Center for providing the transformed MeCP2-luciferase mouse fibroblast cells (clones Xi8 and Xa3). We thank Prof. Brunella Franco for the gift of the hybrid cell lines. We thank the International Rett Syndrome Foundation and the Structural Genomics Consortium at the University of North Carolina for providing the SMART library and Published Kinase Inhibitor Sets (PKIS-1 and 2), respectively. We thank the NIMH Psychoactive Drug Screening Program (B.L. Roth) and the Michael Hooker Chair of Translational Proteomics (B.L. Roth) for providing screening facilities. We thank Phil Avner for the critical reading of the manuscript and support.

\section{Authors' contributions}

HML designed and performed screening and experiments in fibroblast and cortical neurons. NRB, LG, and AC designed and performed experiments in the hybrid cell line and the RNA-FISH in the C2C12 line. MBK, EPC, and MA assisted and supported cell culture, neuronal isolation, and mouse colony maintenance. JMS provided bioinformatic insights. AK and SB performed HAT selection experiments in H4SV cells. NS assisted in image analysis. BDP was responsible for overseeing and leading the work. The manuscript was written by AC, HML, and BDP with input from all the authors. All authors reviewed and agreed to submit the final manuscript. Bryan Roth for support. We thank Francisco Rodriguez Algarra for the help with the statistical analysis.

\section{Authors' information}

N.A.

\section{Funding}

The work was supported by a grant from the Rett Syndrome Research Trust (reverserett.org) and NIH grant R01NS114086 to BDP and a NARSAD Young Investigator Grant (Grant \# 22587) from the Brain \& Behavior Research Foundation to HML. AC and NRB were supported by a Rett Syndrome Research Trust grant (reverserett.org) and Queen Mary University of London intramural support. J.M.S. was supported by The Eunice Kennedy Shriver National Institute of Child Health and Human Development (U54HD079124) and NINDS (P30NS045892). S.B. is the Hartwell investigator. Microscopy was performed at the UNC Neuroscience Microscopy Core Facility, supported, in part, by funding from the NIH-NINDS Neuroscience Center Support Grant P3ONS045892 and the NIH-NICHD Intellectual and Developmental Disabilities Research Center Support Grant U54HD079124.

\section{Availability of data and materials}

All data generated or analyzed during this study are included in this published article and its supplementary information files.

\section{Ethics approval and consent to participate}

N.A.

\section{Consent for publication}

N.A.

\section{Competing interests}

The authors declare no competing interests. 


\section{Author details}

'Department of Cell Biology \& Physiology, University of North Carolina School of Medicine, Chapel Hill, NC, USA. UNC Neuroscience Center, Carolina Institute for Developmental Disabilities, University of North Carolina School of Medicine, Chapel Hill, NC, USA. ${ }^{3}$ Current Address: High-Throughput Bioscience Center, Chemical Biology \& Therapeutics, St. Jude Children's Research Hospital, Memphis, TN, USA. ${ }^{4}$ Blizard Institute, Queen Mary University of London, London, UK. ${ }^{5}$ Department of Biochemistry and Molecular Genetics, Department of Neuroscience, University of Virginia School of Medicine, Charlottesville, VA, USA. ${ }^{6}$ Department of Pharmacology, University of North Carolina School of Medicine, Chapel Hill, NC, USA. ${ }^{7}$ Department of Genetics, University of North Carolina School of Medicine, Chapel Hill, NC, USA.

\section{Received: 15 January 2020 Accepted: 22 October 2020} Published online: 10 November 2020

\section{References}

1. Amir RE, Van den Veyver IB, Wan M, Tran CQ, Francke U, Zoghbi HY. Rett syndrome is caused by mutations in X-linked MECP2, encoding methylCpG-binding protein 2. Nature Genetics. 1999;23(2):185-8.

2. Degano AL, Pasterkamp RJ, Ronnett GV. MeCP2 deficiency disrupts axonal guidance, fasciculation, and targeting by altering Semaphorin $3 \mathrm{~F}$ function. Mol Cell Neurosci. 2009:42(3):243-54

3. Matarazzo V, Cohen D, Palmer AM, Simpson PJ, Khokhar B, Pan SJ, Ronnett $\mathrm{GV}$. The transcriptional repressor Mecp2 regulates terminal neuronal differentiation. Mol Cell Neurosci. 2004;27(1):44-58.

4. Noutel J, Hong YK, Leu B, Kang E, Chen C. Experience-dependent retinogeniculate synapse remodeling is abnormal in MeCP2-deficient mice. Neuron. 2011;70(1):35-42.

5. Cohen S, Gabel HW, Hemberg M, Hutchinson AN, Sadacca LA, Ebert DH, Harmin DA, Greenberg RS, Verdine VK, Zhou Z, et al. Genome-wide activitydependent MeCP2 phosphorylation regulates nervous system development and function. Neuron. 2011;72(1):72-85.

6. Tropea D, Giacometti E, Wilson NR, Beard C, McCurry C, Fu DD, Flannery R, Jaenisch R, Sur M. Partial reversal of Rett syndrome-like symptoms in MeCP2 mutant mice. Proc Natl Acad Sci U S A. 2009;106(6):2029-34

7. Pacheco NL, Heaven MR, Holt LM, Crossman DK, Boggio KJ, Shaffer SA, Flint $\mathrm{DL}$, Olsen ML. RNA sequencing and proteomics approaches reveal novel deficits in the cortex of Mecp2-deficient mice, a model for Rett syndrome. Mol Autism. 2017:8:56.

8. Buchovecky CM, Turley SD, Brown HM, Kyle SM, McDonald JG, Liu B, Pieper AA, Huang W, Katz DM, Russell DW, et al. A suppressor screen in Mecp2 mutant mice implicates cholesterol metabolism in Rett syndrome. Nat Genet. 2013;45(9):1013-20.

9. Mellen M, Ayata P, Dewell S, Kriaucionis S, Heintz N. MeCP2 binds to 5hmC enriched within active genes and accessible chromatin in the nervous system. Cell. 2012;151(7):1417-30.

10. Ballestar E, Yusufzai TM, Wolffe AP. Effects of Rett syndrome mutations of the methyl-CpG binding domain of the transcriptional repressor MeCP2 on selectivity for association with methylated DNA. Biochemistry. 2000;39(24):7100-6.

11. Della Sala G, Pizzorusso T. Synaptic plasticity and signaling in Rett syndrome. Dev Neurobiol. 2014;74(2):178-96.

12. Chahrour M, Zoghbi HY. The story of Rett syndrome: from clinic to neurobiology. Neuron. 2007;56(3):422-37.

13. Weaving LS, Ellaway CJ, Gecz J, Christodoulou J. Rett syndrome: clinical review and genetic update. J Med Genet. 2005;42(1):1-7.

14. Vignoli A, Savini MN, Nowbut MS, Peron A, Turner K, La Briola F, Canevini MP. Effectiveness and tolerability of antiepileptic drugs in 104 girls with Rett syndrome. Epilepsy Behav. 2017;66:27-33.

15. Pintaudi M, Calevo MG, Vignoli A, Baglietto MG, Hayek Y, Traverso M, Giacomini T, Giordano L, Renieri A, Russo S, et al. Antiepileptic drugs in Rett syndrome. Eur J Paediatr Neurol. 2015;19(4):446-52.

16. Grosser E, Hirt U, Janc OA, Menzfeld C, Fischer M, Kempkes B, Vogelgesang S, Manzke TU, Opitz L, Salinas-Riester G, et al. Oxidative burden and mitochondrial dysfunction in a mouse model of Rett syndrome. Neurobiol Dis. 2012;48(1):102-14.

17. Mironov SL, Skorova E, Hartelt N, Mironova LA, Hasan MT, Kugler S. Remodelling of the respiratory network in a mouse model of Rett syndrome depends on brain-derived neurotrophic factor regulated slow calcium buffering. J Physiol. 2009;587(Pt 11):2473-85.

18. Rossignol DA, Frye RE. Melatonin in autism spectrum disorders: a systematic review and meta-analysis. Dev Med Child Neurol. 2011;53(9):783-92.

19. Nomura Y, Honda K, Segawa M. Pathophysiology of Rett syndrome. Brain Dev. 1987:9(5):506-13.

20. Jefferson A, Leonard H, Siafarikas A, Woodhead H, Fyfe S, Ward LM, Munns C, Motil K, Tarquinio D, Shapiro JR, et al. Clinical guidelines for management of bone health in Rett syndrome based on expert consensus and available evidence. PLoS One. 2016;11(2):e0146824.

21. Cerase A, Pintacuda G, Tattermusch A, Avner P. Xist localization and function: new insights from multiple levels. Genome Biol. 2015;16:166.

22. Almeida M, Pintacuda G, Masui O, Koseki Y, Gdula M, Cerase A, Brown D, Mould A, Innocent C, Nakayama M, et al. PCGF3/5-PRC1 initiates Polycomb recruitment in X chromosome inactivation. Science. 2017;356(6342):1081-4.

23. Cerase A, Smeets D, Tang YA, Gdula M, Kraus F, Spivakov M, Moindrot B, Leleu M, Tattermusch A, Demmerle J, et al. Spatial separation of Xist RNA and polycomb proteins revealed by superresolution microscopy. Proc Natl Acad Sci U S A. 2014;111(6):2235-40.

24. Chu C, Zhang QC, da Rocha ST, Flynn RA, Bharadwaj M, Calabrese JM, Magnuson T, Heard E, Chang HY. Systematic discovery of Xist RNA binding proteins. Cell. 2015;161(2):404-16.

25. Moindrot B, Cerase A, Coker H, Masui O, Grijzenhout A, Pintacuda G Schermelleh L, Nesterova TB, Brockdorff N. A pooled shRNA screen identifies Rbm15, Spen, and Wtap as factors required for Xist RNA-mediated silencing. Cell Rep. 2015;12(4):562-72.

26. Monfort A, Di Minin G, Postlmayr A, Freimann R, Arieti F, Thore S, Wutz A. Identification of Spen as a crucial factor for Xist function through forward genetic screening in haploid embryonic stem cells. Cell Rep. 2015:12(4):554-61.

27. Minajigi A, Froberg JE, Wei C, Sunwoo H, Kesner B, Colognori D, Lessing D, Payer B, Boukhali M, Haas W, et al. Chromosomes. A comprehensive Xist interactome reveals cohesin repulsion and an RNA-directed chromosome conformation. Science. 2015;349(6245). https://science.sciencemag.org/ content/349/6245/aab2276/tab-pdf.

28. McHugh CA, Chen CK, Chow A, Surka CF, Tran C, McDonel P, Pandya-Jones A, Blanco M, Burghard C, Moradian A, et al. The Xist IncRNA interacts directly with SHARP to silence transcription through HDAC3. Nature. 2015; 521(7551):232-6.

29. Chen CK, Blanco M, Jackson C, Aznauryan E, Ollikainen N, Surka C, Chow A, Cerase A, McDonel P, Guttman M. Xist recruits the X chromosome to the nuclear lamina to enable chromosome-wide silencing. Science. 2016; 354(6311):468-72

30. Bhatnagar S, Zhu X, Ou J, Lin L, Chamberlain L, Zhu LJ, Wajapeyee N, Green MR. Genetic and pharmacological reactivation of the mammalian inactive $X$ chromosome. Proc Natl Acad Sci U S A. 2014;111(35):12591-8

31. Lessing D, Dial TO, Wei C, Payer B, Carrette LL, Kesner B, Szanto A, Jadhav A, Maloney DJ, Simeonov $A$, et al. A high-throughput small molecule screen identifies synergism between DNA methylation and Aurora kinase pathways for X reactivation. Proc Natl Acad Sci U S A. 2016;113(50):14366-71.

32. Przanowski P, Wasko U, Zheng Z, Yu J, Sherman R, Zhu LJ, McConnell MJ, Tushir-Singh J, Green MR, Bhatnagar S. Pharmacological reactivation of inactive X-linked Mecp2 in cerebral cortical neurons of living mice. Proc Nat Acad Sci U S A. 2018;115(31):7991-6.

33. Sripathy $S$, Leko V, Adrianse RL, Loe T, Foss EJ, Dalrymple E, Lao U, Gatbonton-Schwager T, Carter KT, Payer B, et al. Screen for reactivation of MeCP2 on the inactive X chromosome identifies the BMP/TGF-beta superfamily as a regulator of XIST expression. Proc Natl Acad Sci U S A. 2017; 114(7):1619-24

34. Chan KM, Zhang H, Malureanu L, van Deursen J, Zhang Z. Diverse factors are involved in maintaining $X$ chromosome inactivation. Proceedings of the National Academy of Sciences of the United States of America. 2011;108(40): 16699-704.

35. Fan G, Beard C, Chen RZ, Csankovszki G, Sun Y, Siniaia M, Biniszkiewicz D, Bates $B$, Lee PP, Kuhn R, et al. DNA hypomethylation perturbs the function and survival of CNS neurons in postnatal animals. J Neurosci. 2001;21(3):788-97.

36. Huang HS, Allen JA, Mabb AM, King IF, Miriyala J, Taylor-Blake B, Sciaky N, Dutton JW Jr, Lee HM, Chen X, et al. Topoisomerase inhibitors unsilence the dormant allele of Ube3a in neurons. Nature. 2011;481(7380):185-9.

37. D'Esposito M, Ciccodicola A, Gianfrancesco F, Esposito T, Flagiello L, Mazzarella R, Schlessinger D, D'Urso M. A synaptobrevin-like gene in the 
Xq28 pseudoautosomal region undergoes X inactivation. Nat Genet. 1996; 13(2):227-9.

38. Yaffe D, Saxel O. Serial passaging and differentiation of myogenic cells isolated from dystrophic mouse muscle. Nature. 1977;270(5639):725-7.

39. Kim Y, Lee HM, Xiong Y, Sciaky N, Hulbert SW, Cao X, Everitt JI, Jin J, Roth $\mathrm{BL}$, Jiang YH. Targeting the histone methyltransferase G9a activates imprinted genes and improves survival of a mouse model of Prader-Willi syndrome. Nat Med. 2017;23(2):213-22.

40. Carpenter AE, Jones TR, Lamprecht MR, Clarke C, Kang IH, Friman O, Guertin DA, Chang JH, Lindquist RA, Moffat J, et al. CellProfiler: image analysis software for identifying and quantifying cell phenotypes. Genome Biol. 2006; 7(10):R100.

41. Lyst MJ, Ekiert R, Ebert DH, Merusi C, Nowak J, Selfridge J, Guy J, Kastan NR, Robinson ND, de Lima AF, et al. Rett syndrome mutations abolish the interaction of MeCP2 with the NCoR/SMRT co-repressor. Nat Neurosci. 2013; 16(7):898-902

42. Rahaman SO, Harbor PC, Chernova O, Barnett GH, Vogelbaum MA, Haque SJ. Inhibition of constitutively active Stat3 suppresses proliferation and induces apoptosis in glioblastoma multiforme cells. Oncogene. 2002;21(55): 8404-13.

43. Arany I, Megyesi JK, Nelkin BD, Safirstein RL. STAT3 attenuates EGFRmediated ERK activation and cell survival during oxidant stress in mouse proximal tubular cells. Kidney Int. 2006;70(4):669-74.

44. Thompson JE, Cubbon RM, Cummings RT, Wicker LS, Frankshun R, Cunningham BR, Cameron PM, Meinke PT, Liverton N, Weng Y, et al. Photochemical preparation of a pyridone containing tetracycle: a Jak protein kinase inhibitor. Bioorg Med Chem Lett. 2002;12(8):1219-23.

45. Tang Y, Luo Y, Jiang Z, Ma Y, Lin CJ, Kim C, Carter MG, Amano T, Park J, Kish $\mathrm{S}$, et al. Jak/Stat3 signaling promotes somatic cell reprogramming by epigenetic regulation. Stem Cells. 2012;30(12):2645-56.

46. De Bonis ML, Cerase A, Matarazzo MR, Ferraro M, Strazzullo M, Hansen RS, Chiurazzi P, Neri G, D'Esposito M. Maintenance of X-and Y-inactivation of the pseudoautosomal (PAR2) gene SPRY3 is independent from DNA methylation and associated to multiple layers of epigenetic modifications. Human Mol Genet. 2006;15(7):1123-32.

47. Matarazzo MR, De Bonis ML, Strazzullo M, Cerase A, Ferraro M, Vastarelli P, Ballestar E, Esteller M, Kudo S, D'Esposito M. Multiple binding of methyl-CpG and polycomb proteins in long-term gene silencing events. J Cell Physiol. 2007:210(3):711-9.

48. Gontan C, Achame EM, Demmers J, Barakat TS. Rentmeester E, van IW, Grootegoed JA, Gribnau J: RNF12 initiates X-chromosome inactivation by targeting REX1 for degradation. Nature. 2012;485(7398):386-90.

49. Kolpa HJ, Fackelmayer FO, Lawrence JB. SAF-A requirement in anchoring XIST RNA to chromatin varies in transformed and primary cells. Dev Cell. 2016;39(1):9-10.

50. Nicolas CS, Amici M, Bortolotto ZA, Doherty A, Csaba Z, Fafouri A, Dournaud $P$, Gressens P, Collingridge GL, Peineau S. The role of JAK-STAT signaling within the CNS. JAKSTAT. 2013;2(1):e22925.

\section{Publisher's Note}

Springer Nature remains neutral with regard to jurisdictional claims in published maps and institutional affiliations.

Ready to submit your research? Choose BMC and benefit from:

- fast, convenient online submission

- thorough peer review by experienced researchers in your field

- rapid publication on acceptance

- support for research data, including large and complex data types

- gold Open Access which fosters wider collaboration and increased citations

- maximum visibility for your research: over $100 \mathrm{M}$ website views per year

At $\mathrm{BMC}$, research is always in progress.

Learn more biomedcentral.com/submissions 